ISSN 0103-5150

Fisioter. Mov., Curitiba, v. 30, n. 3, p. 473-484, Jul./Sep. 2017

Licenciado sob uma Licença Creative Commons

DOI: http://dx.doi.org/10.1590/1980-5918.030.003.A005

\title{
Association between kinesiologic dysfunctions, lumbar disability and lumbopelvic pain in pregnancy
}

\author{
Associação entre disfunções cinético-funcionais, \\ incapacidade lombar e dor lombopélvica na gestação
}

\author{
Letícia Fujimaki de Paula ${ }^{[a]}$, Raíssa Gabriela Cabral Silva ${ }^{[a]}$, Letícia Fernandes Andres ${ }^{[b]}$, \\ Raciele Ivandra Guarda Korelo ${ }^{[\mathrm{c}]^{*}}$
}

[a] Universidade Federal do Paraná (UFPR), Matinhos, PR, Brazil

[b] Secretaria de Saúde de Pontal do Paraná, Pontal do Paraná, PR, Brazil

[c] Universidade Federal do Paraná (UFPR), Curitiba, PR, Brazil

\begin{abstract}
Introduction: Low back pain in pregnancy is highly prevalent and multifactorial. However, it is still unclear if the back pain is associated with functional kinetic changes that occur during pregnancy. Objective: To evaluate the occurrence of low back pain in pregnancy and to investigate the association of low back pain disability with intensity, pain origin and kinesilogic dysfunction (range of motion of the lumbar spine, lumbar flexibility and trunk mobility). Methods: Women $(n=32)$ with gestational age equal or less than 20 weeks, assisted in one health centers on the coast of Paraná. Obstetric and historical lumbopelvic of pain, musculoskeletal discomfort, intensity lumbopelvic pain, low back disability, the source of pain through specific clinical trials, joint range of motion of the lumbar spine, the lumbar flexibility and general mobility of the trunk were evaluated. Results: The lumbar region was the most reported and higher frequency $(\mathrm{p}=$ 0.000 ) for the occurrence of musculoskeletal discomforts. The prevalence of lumbopelvic pain was $93.8 \%$. Most reported the first episode after the 14th week of pregnancy (90\%), on a daily frequency (63.3\%), high
\end{abstract}

LFP: BS, e-mail: lee.fujimaki@gmail.com

RGCS: BS, e-mail: rahgabi@gmail.com

LFA: BS, e-mail: alentricia@hotmail.com

RIGK: PhD, e-mail: raciele@ufpr.br 
intensity (50\%), limiting the activities of daily living (50\%) and generating low back disability (moderate to severe in 56.9\%). Lumbar disability levels were significantly correlated to gestational age $(r=0.353)$, pain intensity $(r=0.402)$, positive results in clinical trials (except for the Lasègue test), range of motion for flexion $(r=-0.280)$ and lumbar extension $(r=-0.301)$, lumbar flexibility $(r=-0.371)$ and general mobility trunk $(r=0.503)$. Conclusion: The greater gestational age, the greater intensity of pain, positivity in clinical trials, decreased range of motion, flexibility and lumbar trunk mobility constitute major lumbar disability.

Keywords: Low Back Pain. Pelvic Pain. Pregnancy. Pregnancy Complications.

\section{Resumo}

Introdução: Lombalgia gestacional é de alta prevalência e multifatorial. No entanto, ainda não está totalmente esclarecido se a dor lombar está associada com as alterações cinético funcionais que ocorrem na gestação. Objetivo: Estimar a ocorrência de lombalgia gestacional e verificar a associação da incapacidade de dor lombar com intensidade, origem da dor e disfunções cinético funcionais (amplitude de movimento da coluna lombar, flexibilidade lombar e mobilidade do tronco). Métodos: Mulheres $(n=32)$ com idade gestacional igual ou superior a 20 semanas, assistidas em um centro de saúde do litoral do Paraná. Foram avaliados dados obstétricos e históricos da dor lombopélvica, desconfortos musculoesqueléticos, intensidade da dor lombopélvica, a incapacidade lombar, a origem da dor por meio de testes clínicos específicos, amplitude de movimento articular da coluna lombar, a flexibilidade lombar e a mobilidade geral do tronco. Resultados: A região lombar foi a mais relatada e de maior periodicidade $(p=0.000)$ para a ocorrência de desconfortos musculoesqueléticos. A prevalência da dor lombopélvica foi de 93,8\%. A maioria relatou o primeiro episódio após a 14a semana gestacional (90\%), com frequência diária (63,3\%), de alta intensidade (50\%), limitando as atividades de vida diária (50\%) e gerando incapacidade lombar (moderada a severa para 56,9\%). Os níveis de incapacidade lombar apresentaram correlação significativa para idade gestacional $(r=0,353)$, intensidade da dor $(r=0,402)$, positividade nos testes clínicos (exceto para o teste de Lásegue), amplitude articular para flexão $(r=-0,280)$ e extensão lombar $(r=-0,301)$, flexibilidade lombar $(r=-0,371)$ e mobilidade geral de tronco $(r=0,503)$. Conclusão: Maior idade gestacional, maior intensidade da dor, positividade nos testes clínicos, menor amplitude articular, menor flexibilidade lombar e menor mobilidade de tronco acarretam maior incapacidade lombar.

Palavras-chave: Dor Lombar. Dor Pélvica. Gestação. Complicações na Gravidez.

\section{Introduction}

Musculoskeletal discomforts are experienced during pregnancy, causing impacting everyday limitations on life quality $(1,2)$. Among these discomforts, lumbopelvic pain has received much attention in the last years by the scientific community $(3,4,5,6,7)$. It is estimated that lumbopelvic pain affects one in two pregnant women, causing great concern (8). Basing on that concern, its high prevalence, intensity and discomfort, the pain limits daily life activities, reason why most of the sick days occur on this period of time $(7,8,9)$.

For example, Vermani et al. (10) reported that the pain lumbopelvic starts from 18 gestational weeks, and the highest intensities occur between the 24th to 36th week. Malmqvist et al. (4) reported that most women who develop moderate to severe pain, had this symptom from the 20th gestational week.

According to research conducted in Brazil, the prevalence of gestational lumbopelvic pain ranges from $73 \%$ to $95.2 \%(11,12,13,14)$. This variation may be due to differences in the population of the study, the evaluation period (before or after gestational period), the study design (prospective, crosssectional or retrospective) or due to their different forms of presentation (low back pain, pelvic pain or combination of both), known popularly, regardless of the origin of pain and characterization, as low back pain in pregnancy (5).

Despite its high prevalence, factors associated with this condition are not yet fully clear. Lumbopelvic 
pain in pregnancy has a multifactorial etiology and is related to physiological factors, biomechanics, vascular, psychological and hormonal (6). By involving the combination of several factors, this painful condition is not yet fully understood and little is known about the relationship between the disability caused by this condition with the limitations and functional kinetic disorders of the lumbar spine.

Thus, we investigate the musculoskeletal discomfort expressed by pregnant women and their frequency. Also to estimate the occurrence of lumbopelvic pain and to describe its main characteristics and triggering/aggravating factors. Then, the purpose of this paper is to determine the association of low back pain disability with history, intensity and origin of the pain, and the association with functional kinetic disorders, such as range of motion of the lumbar spine, lumbar flexibility and trunk mobility.

\section{Methods}

\section{Study design}

This research is an exploratory and descriptive cross-sectional study with non probabilistic convenience sample. The study was approved by the Ethics in Research of the Health Sciences Sector of the Federal University of Paraná Committee (504.452), under Resolution 466/12 of the National Health Council, conducted according to the Helsinki Declaration revised in 2008, and it was registered in the Brazilian Registry of Clinical Trials (RBR-7pbcdw).

This study included pregnant women enrolled for the program Happy Mother of the Health Secretary of Pontal do Paraná - Brazil, aged between 18-35 years and gestational age greater than or equal to 20 weeks, representing more than $50 \%$ of pregnant women in those health centers. They excluded those with a clinical diagnosis of high-risk pregnancy; twins pregnancy; presence of cognitive/mental disabilities; urinary tract infection; neurological dysfunction; herniated lumbar disc; and previous surgery in the spine, pelvis, hip or knee.

For sample size calculation, we assumed the proportion of pregnant women in $8.51 \%$ (236) of all women of the city in the age group 15-39 years (3.525), according to the latest report (2009) available on the Data SUS (Tabnet) for the municipality.
The formula (1) used for that is below, with a 95\% confidence interval and 5\% sampling error:

$$
\mathrm{n}=\frac{\mathrm{z}_{\alpha / 2}^{2} * \mathrm{~N} * \mathrm{P} *(1-\mathrm{P})}{\varepsilon^{2}(\mathrm{~N}-1)+\mathrm{z}_{\alpha / 2}^{2} *(1-\mathrm{P})}
$$

Where: $\mathrm{n}$ - sample size to be calculated; $\mathrm{z}_{\alpha / 2}^{2}$ - critical value to the desired degree of confidence; $\mathrm{N}$ population size; $\mathrm{P}$ - population proportion of pregnant women in the municipality of Pontal do Paraná; $\varepsilon^{2}$ : - sampling error. Assuming these parameters, the result was 68 pregnant women.

For this study, pregnant women were enrolled in the program for the period (from March to August / 2104) who met the inclusion criteria $(n=65)$, but 32 were included (Figure 1). While they were waiting their consultation with an obstetrician and/or physiotherapist in the Health Center, they were invited to participate in the study individually and after explanation about that, they signed written consent.

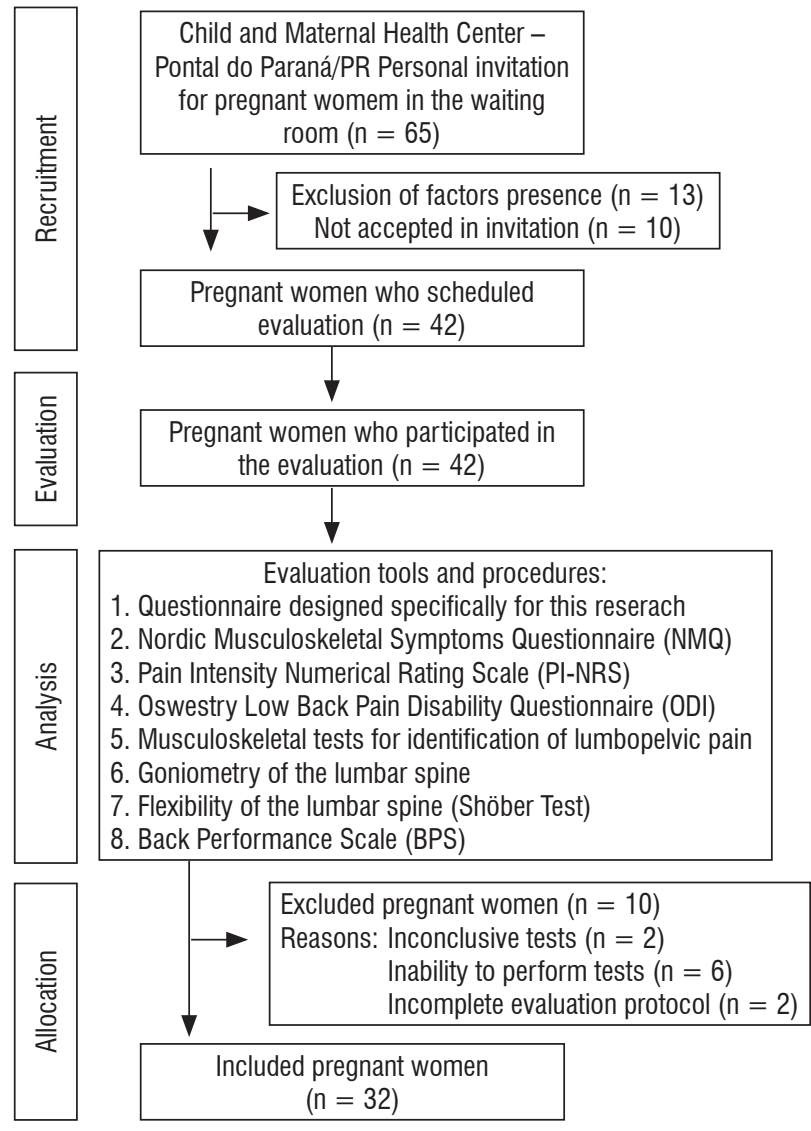

Figure 1 - Experimental design with flow diagram regarding the stages of study 
Experimental procedure

The participants were evaluated with:

1) Questionnaire designed specifically for the research: the questionnaire contained socio demographic, obstetric and historical low back pain data;

2) Nordic Musculoskeletal Symptoms Questionnaire validated in Brazil (15): to evaluate the occurrence of musculoskeletal symptoms of pain, numbness, tingling or discomfort in the nine regions of the body (neck, shoulder, arms, elbows, forearms, wrists/hands/fingers, dorsal, lower back and hip/ lower limbs), from the 4-point Likert scale (no, rarely, often and always). Study participants reported the occurrence of symptoms considering the gestational months and seven days prior to the interview;

3) Pain Intensity Numerical Rating Scale (PI-NRS) (16): to evaluate the intensity of low back pain in the seven days preceding the interview was used 11-point pain intensity numerical rating scale that consists of 11 numbers from 0 (no pain) to 10 (maximum pain) in a horizontal line associated with facial expressions;

4) Oswestry Lowe Back Pain Disability Questionnaire or ODI (Oswestry Disability Index) validation into Portuguese language (17): to evaluate the lumbar disability index. It consists of 10 questions in 6-point Likert scale where the highest score indicates greater functional limitation. The total score was calculated by summing the points transformed into percentage and interpreted as follows: 0 to $20 \%$ $=$ minimal disability; 20 to $40 \%=$ moderate disability; 40 to $60 \%=$ severe disability; 60 to $80 \%$ = very severe disability; 80 and $100 \%=$ complete failure.

5) Musculoskeletal clinical tests to identify the lumbopelvic pain: six clinical trials were selected, conducted by the same examiner to identify the origin and site of low back pain: provocation test lumbar pain (18), Laségue test (19), SLR - Straight Leg Raise test (19), PPPP - Posterior Pelvic Pain Provocation test $(5,18,20)$, Gaenslen test $(19,20)$ and ASLR Active Straight Leg Raise $(5,20)$. The PPPP, due to stretching of structures of this region, allows the detection of the presence of pain in pregnant women $(11,18)$. The other two tests, Gaenslen test and ASLR, were chosen because they are established in the literature on differential diagnosis of the lower back pain source with neural involvement (18). The last three tests are recommended by European community (20) and different authors $(5,10,18,21)$ as reliable tests for the diagnosis of posterior pelvic pain. So for statistical analysis and confirmation of these claims, in our study the following criteria was established for defining the location of pain: a positive result in, at least, two of the first three tests, the pain was rated as lumbar origin. And in positivity cases, at least, two of the last three tests, the pain was rated as sacroiliac or posterior pelvic origin. If the participants presented positive result in two of three tests lumbar origin associated with positivity in two of three tests of sacroiliac origin, pain was rated as the origin in both regions.

6) Goniometry of lumbar spine: to measure the maximum range active joint of the lumbar spine in degrees was used goniometry protocol (22) of the lumbar spine (flexion, extension, lateral flexion and rotation on both sides), with the $20 \mathrm{~cm}$ goniometer $\left(\mathrm{Carci}^{\circledR}\right)$, by the same examiner.

7) Schober Test (19): in order to check the lumbosacral flexibility of the study participants.

8) Back Performance Scale (23): used to check overall trunk mobility and physical performance. It consists of 5 standardized tests (Sock Test, Pick-up Test, Roll-up Test, Fingertip-to-Floor Test and Lift Test). The score for each test was graded as 0 (can easily perform), 1 (can perform with less effort), 2 (can perform with effort) and 3 (does not perform completely or needs help), all of which are added to the general score.

\section{Statistical analysis}

The Statistical Package for the Social Sciences (SPSS) software, version 21.0 for Windows was used. In their totality, the data were submitted to the Shapiro Wilk test to test the normality of distribution. The categorical variables were described in absolute frequency (n) and relative frequency (\%), while numerical variables were described in mean \pm standard error of the mean.

For the analysis of the origin of the low back pain and the data referring to the Nordic Musculoskeletal Questionnaire the Pearson chi-square test was used, corrected by the Likelihood Ratio for small samples. The level of significance was set at $\mathrm{p}<0.05$.

Aiming to identify aggravating factors for the functional limitation of the lumbar spine (ODI), correlation tests were performed by individually associating each variable collected with the score obtained in 
the ODI. For the parametric data the Pearson correlation test was used and the level of significance was set at $\mathrm{p}<0.05$. The magnitude scale (24) used to interpret the correlation coefficients was considered: $\mathrm{r}<0.1$ = trivial; between $0.1-0.29=$ small; $0.30-0.49$ $=$ moderate; $0.50-0.69=$ high; $0.70-0.90=$ very high and $\mathrm{r}>0.90=$ almost perfect.

\section{Results}

Table 1 shows the characteristics of the sample.

Table 1 - Sociodemographic and obstetric characteristics.

\begin{tabular}{|c|c|}
\hline \multicolumn{2}{|l|}{ Variable } \\
\hline Age in years (mean \pm SEM) & $25.72 \pm 1.02$ \\
\hline Gestational age in weeks (mean \pm SEM) & $30.09 \pm 1.11$ \\
\hline \multicolumn{2}{|l|}{ Schooling (n, \%) } \\
\hline Incomplete Middle School & $2(6.3)$ \\
\hline Complete Middle School & $2(6.3)$ \\
\hline Incomplete High School & $5(15.6)$ \\
\hline Complete High School & $13(40.6)$ \\
\hline Incomplete Higher Education & $6(18.8)$ \\
\hline Graduated & $4(12.5)$ \\
\hline \multicolumn{2}{|l|}{ Occupation (n,\%) } \\
\hline Housewife & $16(50)$ \\
\hline Student & $3(9.4)$ \\
\hline Teacher & $3(9.4)$ \\
\hline Others & $10(31.3)$ \\
\hline \multicolumn{2}{|l|}{ Physical Activity Practice (n, \%) } \\
\hline Walking & $3(9.4)$ \\
\hline Gym & $14(43.8)$ \\
\hline Yoga & $1(3.1)$ \\
\hline Does not practice & $14(43.8)$ \\
\hline \multicolumn{2}{|l|}{ Number of pregnancies (n, \%) } \\
\hline Only one & $12(37.5)$ \\
\hline Two & $12(37.5)$ \\
\hline Three & $4(12.5)$ \\
\hline Four or more & $4(12.5)$ \\
\hline \multicolumn{2}{|l|}{ Number of Abortions (n, \%) } \\
\hline None & $26(81.3)$ \\
\hline Only one & $5(15.6)$ \\
\hline Two & $1(3.1)$ \\
\hline \multicolumn{2}{|l|}{ Number of vaginal deliveries (n, \%) } \\
\hline None & $18(56.3)$ \\
\hline Only one & $8(25)$ \\
\hline Two & $3(9.4)$ \\
\hline Three & $3(9.4)$ \\
\hline \multicolumn{2}{|l|}{ Number of cesarean deliveries (n, \%) } \\
\hline None & $29(90.6)$ \\
\hline Only one & $3(9.4)$ \\
\hline
\end{tabular}

Note: SEM = Standard Error of the Mean.
Regarding to the history of low back pain, 13 (40.6\%) women reported their occurrence before gestation, with frequency of two to more times per month for most of them (46.2\%), followed by only once a month (23.1\%), and two more times each 6 months (30.8\%). Interestingly, of the 13 women only $4(30.7 \%)$ were under treatment (medicated) and $69.3 \%$ did not undergo any treatment for symptom relief. Differently, during pregnancy, 30 (93.8\%) pregnant women reported the presence of low back pain, and the majority ( $90 \%$ ) had the first episode of pain after 14 gestational weeks, against only $10 \%$ of them experiencing this condition in the first trimester of Gestation. The daily frequency of this condition was reported by $63.3 \%$ of the pregnant women in the last four weeks; $23.3 \%$ with a frequency of 3 to 6 times a week and $10 \%$ of 1 to 2 times a week, and only $10 \%$ sought treatment for this condition. Still, the longterm walk without professional guidance/follow-up was cited as the main triggering factor in $36.7 \%$ of pregnant women, and the fact of lying down, sitting or relaxing, decreased pain by $76.7 \%$.

A survey of the occurrence of musculoskeletal discomfort using the Nordic Musculoskeletal Questionnaire revealed that the presence of pain, tingling or numbness in the lumbar region was the most reported (90.6\%) in the different gestational months, followed by the dorsal region (62.5\%) and the hip region $(56.2 \%)$, neck (40.7\%), ankle/feet (34.3\%), wrists/hands (31.3\%), shoulders $(28.1 \%)$, knees (15.6\%) and elbows (3.1\%). Thus, the discomforts felt in the lumbar region were responsible for preventing the activities of daily living in $50 \%$ of pregnant women. Still, from the 32 pregnant women evaluated, $25(78.1 \%)$ reported the presence of pain in this region in the last 7 days. Pearson's chi-square test (corrected by the Likelihood Ratio) applied to verify the periodicity of the referred symptom in the different regions showed that the lumbar region was the only one, as always, present in the gestational period, $\chi^{2}(3, n=30)=17.75, p=0.000$, differing from the others when compared statistically to other frequency possibilities, most often reported to other regions as never before.

From the 30 pregnant women who reported pain on the initial questionnaire, their intensity was graded by PI-NRS, which presented a median of $7.5(0-10)$, being classified as low to $6.7 \%$, moderate to $43.3 \%$, and intense to $50 \%$. The lumbar 
disability index assessed from the ODI revealed a mean of $23.9 \pm 3.2$ points, the majority $(40.6 \%$ ) being classified as low disability, $37.5 \%$ moderate, $15.6 \%$ severe and $6.3 \%$ very severe.

Through the specific tests of lumbopelvic pain used in this study, it was possible to identify that $23.4 \%$ presented positivity in the tests indicating the sacroiliac/posterior pelvic region as its origin, followed by $36.6 \%$ for low back pain and $40 \%$ presented a combination of the pain site. Positively, all of the specific lumbopelvic pain tests used in this study were associated with the origin of the analyzed pain (lumbar or posterior pelvic region), using the Pearson chi-square test, corrected by the Likelihood Ratio (Table 2). For example, in the tests for verification of sacroiliac pain origin, as in the Posterior Pelvic Pain Provocation test, statistical analyses $\left(\chi^{2}(2, n=\right.$ 30) $=11.29, p=0.004$, Cramer's $V=0.582$ ) suggest that based on the relative risk rule, all those tested positive were 4.6 times more likely to originate from sacroiliac pain than lumbar origin.

Table 2 - Association of symptoms and positivity in specific tests of gestational lumbopelvic pain with the origin/site of pain

\begin{tabular}{|c|c|c|c|c|c|c|c|c|}
\hline $\begin{array}{c}\text { Lumbopelvic pain } \\
\text { test }\end{array}$ & Description & Lumbar & Pelvic & Both & Total & LR & p-value & Cramer's V \\
\hline Lumbar pain provocation & $\begin{array}{l}\text { Positive } \\
\text { Negative }\end{array}$ & $\begin{array}{l}4 \\
7\end{array}$ & $\begin{array}{l}0 \\
7\end{array}$ & $\begin{array}{r}12 \\
0\end{array}$ & $\begin{array}{l}16 \\
14\end{array}$ & 28.16 & $0.000^{*}$ & 0.600 \\
\hline Laségue & $\begin{array}{l}\text { Positive } \\
\text { Negative }\end{array}$ & $\begin{array}{l}3 \\
8\end{array}$ & $\begin{array}{l}1 \\
6\end{array}$ & $\begin{array}{l}8 \\
4\end{array}$ & $\begin{array}{l}12 \\
18\end{array}$ & 6.472 & $0.039 *$ & 0.456 \\
\hline SLR & $\begin{array}{l}\text { Positive } \\
\text { Negative }\end{array}$ & $\begin{array}{l}6 \\
5\end{array}$ & $\begin{array}{l}1 \\
6\end{array}$ & $\begin{array}{r}11 \\
1\end{array}$ & $\begin{array}{l}18 \\
12\end{array}$ & 12.59 & $0.002^{*}$ & 0.612 \\
\hline PPPP & $\begin{array}{l}\text { Positive } \\
\text { Negative }\end{array}$ & $\begin{array}{r}1 \\
10\end{array}$ & $\begin{array}{l}3 \\
4\end{array}$ & $\begin{array}{l}9 \\
3\end{array}$ & $\begin{array}{l}13 \\
17\end{array}$ & 11.295 & $0.004^{*}$ & 0.582 \\
\hline Gaenslen & $\begin{array}{l}\text { Positive } \\
\text { Negative }\end{array}$ & $\begin{array}{r}0 \\
11\end{array}$ & $\begin{array}{l}3 \\
4\end{array}$ & $\begin{array}{r}11 \\
1\end{array}$ & $\begin{array}{l}14 \\
16\end{array}$ & 25.011 & $0.000^{*}$ & 0.805 \\
\hline ASLR & $\begin{array}{l}\text { Positive } \\
\text { Negative } \\
\text { Total }\end{array}$ & $\begin{array}{r}4 \\
7 \\
11\end{array}$ & $\begin{array}{l}2 \\
5 \\
7\end{array}$ & $\begin{array}{r}10 \\
2 \\
12\end{array}$ & $\begin{array}{l}16 \\
14 \\
30\end{array}$ & 7.846 & $0.020^{*}$ & 0.495 \\
\hline
\end{tabular}

Note: * $p<0.05$, Pearson's chi-square test (corrected by Likelihood Ratio). Abbreviations: LR, Likelihood Ratio; SLR, Straight Leg Raise; PPPP, Posterior Pelvic Pain Provocation; ASLR, Active Straight Leg Raise.

The assessment of joint amplitude of the lumbar spine using goniometry revealed that most women presented limitation in all movements, reducing the mean of the maximum active joint amplitude in this sample (Table 3). At the same time, the flexibility of the lumbar spine measured by the Schober test was decreased in $41.9 \%$ of the pregnant women (Table 3).

Likewise, the results obtained by the Back Performance Scale presented, on average, low scores $(8.94 \pm 0.61)$, with the majority classified with moderate limitation in general trunk mobility and physical performance. The tests performed revealed that most of the evaluated ones (53.1\%) did not reach their malleolus to put their Sock Test in need of help to do so; $34.4 \%$ had difficulty reaching objects on the floor, needing support on one or both legs to do it (Pick-up test); 59.4\% presented great limitation to sit from the position of dorsal position (Roll-up test). However, $54.8 \%$ could reach the ground from the orthostatic position with little effort, while $83.8 \%$ presented a low
(46.9\%) to moderate (46.9\%) limitation to support a weight of $5 \mathrm{~kg}$ for one minute (Lift test).

Table 3 - Lumbar spine joint amplitude, lumbar flexibility and general trunk mobility of the evaluated pregnant women

\begin{tabular}{lr}
\hline \multicolumn{1}{c}{ Kinetic-functional characteristics } & Mean \pm SEM \\
\hline Goniometry & \\
Lumbar flexion & $74.77 \pm 3.25$ \\
Lumbar extension & $14.77 \pm 1.21$ \\
Right side flexion & $20.31 \pm 1.13$ \\
Left side flexion & $17.84 \pm 1.11$ \\
Right rotation & $13.90 \pm 1.18$ \\
Left rotation & $16.31 \pm 1.23$ \\
Schober & \\
Flexibility (cm) & \\
Classification (n, \%) & $4.82 \pm 0.22$ \\
$\quad$ Normal & $18(58.1)$ \\
$\quad$ Decreased & $13(41.9)$ \\
Back Performance Scale & $8.94 \pm 0.61$
\end{tabular}

Note: SEM = Standard Error of the Mean. 
The analysis of the correlation of the various variables of the study with lumbar incapacity, quantified by the ODI score are presented in Table 4. Significant positive correlation of moderate magnitude was observed in most of the presented variables, the highest magnitude being the provocation test $(r=0.540)$, presence of pain in the last seven days $(r=0.510)$, Pick-up test $(r=0.565)$ and Back Performance Scale $(r=0.503)$ that presented high magnitude. Lumbar disability also showed moderate correlations to seek professional help to reduce pain $(r=-0.346)$, lower level of lumbar extension measured by goniometry $(r=-0.301)$, and limitation of lumbar flexibility measured by the Schober test $(r=-0.371)$. Furthermore, a significant negative correlation of weak magnitude was observed for a lower degree of lumbar flexion measured by goniometry $(r=-0.280)$.

Table 4 - Correlation of lumbar incapacity (Oswestry Disability Index) with obstetric characteristics, history of low back pain and functional kinetic conditions (specific tests for lumbopelvic pain, lumbar spine articular range of motion, lumbar flexibility and general trunk mobility)

\begin{tabular}{|c|c|c|c|}
\hline Variables & $r$ & $p$-valor & $\overline{R^{2}}$ \\
\hline \multicolumn{4}{|l|}{ Obstetric } \\
\hline Gestational age & 0.353 & $0.006^{*}$ & 0.12 \\
\hline \multicolumn{4}{|l|}{ History of low back pain during pregnancy } \\
\hline Presence of pain during pregnancy & 0.341 & $0.024 *$ & 0.11 \\
\hline Frequency of pain in the last 4 weeks & 0.398 & $0.008^{*}$ & 0.15 \\
\hline Pain worsens when walking & 0.428 & $0.006^{*}$ & 0.18 \\
\hline PI-NRS Score & 0.402 & $0.003^{*}$ & 0.16 \\
\hline PI-NRS Classification & 0.460 & $0.002^{*}$ & 0.21 \\
\hline Seek professional help to decrease pain & -0.345 & $0.027^{\star}$ & 0.11 \\
\hline \multicolumn{4}{|l|}{ Musculoskeletal tests to identify lumbopelvic pain } \\
\hline Lumbar pain provocation & 0.540 & $0.000^{*}$ & 0.29 \\
\hline Straight Leg Raise & 0.373 & $0.013^{*}$ & 0.13 \\
\hline Posterior Pelvic Pain Provocation & 0.356 & $0.018^{*}$ & 0.12 \\
\hline Gaenslen Test & 0.473 & $0.002^{\star}$ & 0.22 \\
\hline Active Straight Leg Raise & 0.455 & $0.003^{*}$ & 0.20 \\
\hline \multicolumn{4}{|l|}{ Lumbar discomfort by Nordic Questionnaire } \\
\hline Impediment of performing physical activities & 0.470 & $0.002^{*}$ & 0.22 \\
\hline Presence of pain in the last 7 days & 0.510 & $0.001^{*}$ & 0.26 \\
\hline \multicolumn{4}{|l|}{ Goniometry } \\
\hline Lumbar flexion & -0.280 & $0.031 *$ & 0.07 \\
\hline Lumbar extension & -0.301 & $0.027^{*}$ & 0.09 \\
\hline Flexibility (Shober in cm) & -0.371 & $0.006^{*}$ & 0.13 \\
\hline \multicolumn{4}{|l|}{ Back Performance Scale } \\
\hline Sock test & 0.338 & $0.017^{*}$ & 0.11 \\
\hline Pick-up test & 0.565 & $0.000^{*}$ & 0.31 \\
\hline Roll-up test & 0.431 & $0.003^{*}$ & 0.18 \\
\hline Fingertip-to-floor test & 0.447 & $0.002^{*}$ & 0.20 \\
\hline Lift test & 0.444 & $0.002^{*}$ & 0.19 \\
\hline Total do Back Performance Scale & 0.503 & $0.000 *$ & 0.25 \\
\hline
\end{tabular}

Note: * Pearson correlation test with significance level of $p<0.05$. Abbreviation: PI-NRS, Pain Intensity Numerical Rating Scale.

\section{Discussion}

This study was conducted with the main objective of relating the lumbar incapacity provided by lumbopelvic pain from the twentieth gestational week with the limitations and kinetic-functional dysfunctions of the lumbar spine. Relevance to this study is due to the fact that up to now, adaptations of the musculoskeletal system during morphophysiological changes of gestation have not yet been fully clarified 
(25), especially those related to kinetic-functional dysfunctions. The strength of the current study is the multidimensional assessment approach used, including specific clinical trials for identification of the origin of low back pain, assessment of range of motion and lumbar flexibility, as well as overall trunk mobility and/or physical performance. The evaluation was performed by a single evaluator, but was limited to only one repetition of each test, making it impossible to evaluate its reliability, due to the long evaluation protocol (an average of 40 minutes). This factor restricted the participation of pregnant women who were waiting for obstetrical consultation, arguing that there was no time to participate in the evaluation. Differently, the pregnant women who were waiting for physical therapy consultation for prenatal orientation did not report this inconvenience. However, the reasons related to this difference were not investigated.

In the present study, musculoskeletal discomforts ascertained by the Nordic Questionnaire during gestation revealed that the lumbar region $(90.6 \%)$ was the most cited for the occurrence of symptoms such as pain, numbness, tingling or discomfort. Still, 78.1\% reported the presence of pain in this region in the last 7 days, being their periodicity the only region to present as always present in the gestational period. This differs from a study (1) conducted in India to validate a questionnaire to identify musculoskeletal discomforts during gestation. In the third gestational trimester, the most frequent discomforts were calf muscle weakness (64.6\%), followed by foot pain (37.1\%), and low back pain (33.7\%). Already, in the second trimester, this study revealed that calf pain was the most frequent complaint (47.8\%), followed by low back pain (42\%) and pelvic pain (37\%). The researchers found that pregnant women experience more of these symptoms during their hygiene activities, when trying to put on their shoes, when getting up from chairs or sitting with the lower limbs in extension. Contradictions in the results may be due to the evaluation instrument used and the cultural and environmental differences experienced by the pregnant women.

Differently, a narrative study (2) on musculoskeletal discomforts in gestation reports the occurrence of low back pain in 50 to $80 \%$ of pregnant women, as the most prevalent. Studies $(11,12,13,14)$ on the prevalence of gestational low back pain in our country have found results similar to ours, ranging from
$73 \%$ to $95.2 \%$. In our study, the majority (63.3\%) of the pregnant women reported experiencing this pain daily, being graded to $50 \%$ of them as high intensity and moderate to severe low back disability to $56.9 \%$ of the sample. Characteristics of gestational low back pain may vary throughout pregnancy, and even in the same pregnancy from one pregnancy to another, because it is assumed to depend on the balance between perceived pain, limitation, and individual ability to seek coping strategies (6). Another study (8) stated that $73 \%$ of the pregnant women reported low back pain, most of them felt as a spike, with daily frequency, duration of at least one hour and average intensity around seven. This same study observed an association of moderate magnitude between pain scores and lumbar incapacity. In contrast to these findings, a study (5) of 182 Dutch women found a prevalence of $60.4 \%$ of pelvic low pain, with a mean score of 3.6 (greater than 5 only $20 \%$ of the sample) and minimal disability measured by the Quebec Back Pain Disability Scale (severe incapacity was found for only $20 \%$ of pregnant women).

We also observed in our study that lumbopelvic pain was responsible for preventing the performance of daily life activities in $50 \%$ of pregnant women, with a positive correlation of moderate magnitude $(r=$ 0.470 ) with lumbar incapacity measured by ODI. Previous study (8) have already suggested that low back pain interferes in some way with the functionality of the pregnant women, with work impairment, generating absenteeism and frequent leaves from work. But it did not take into account the relationship between the degree of disability and the intensity of pain, which is related to the higher number of sick leaves (7). This corroborates our findings, since the greater the intensity of pain $(r=0.402)$ or more severe its classification $(r=0.460)$ by the PI-NRS, the greater the lumbar incapacity, causing difficulties for their productivity. However, contrary to these results, a study (26) of 100 Turkish pregnant women showed no correlation between pain intensity and lumbar incapacity. The different results may be due to the fact that pregnant women included in their study had low values of pain intensities measured by the Visual Analog Scale.

As expected, our study revealed that gestational age is associated with the appearance of this condition, that is, the greater the gestational age, the greater the possibility of occurrence of lumbopelvic pain $(r=0.353)$. The majority ( $90 \%)$ of the pregnant 
women had the first episode of pain after 14 gestational weeks, being compatible with most of the previous studies $(3,4,8,27)$, possibly related to direct fetal pressure against the neural elements of the lumbar spine and greater overload in the lumbar muscles (13).

However, there are differences in the literature regarding the different risk factors. In our study, we observed no association of lumbar disability with age, level of schooling, number of previous births or type of delivery, as previously reported (4) in 569 women. Although these results were contradictory, a study (3) with 1158 women presented an association of gestational low back pain with educational level (corresponding to secondary education) and younger. Possibly, this association may be related to greater sensitivity to the changes in this period, provided by the action of hormones or collagen laxity that is more pronounced in younger women (8).

Unexpectedly, there was no association in our study with reports of pain prior to gestation or the practice of physical activity before or during gestation. Previous reports $(5,8)$ have shown that the presence of pain before pregnancy is a potential risk factor and, conversely, the practice of physical activity is a preventive factor (4). However, corroborating our findings, previous studies $(3,6)$ found no association with previous physical activity or during pregnancy, but found a strong association with a previous history of pain.

Observational (28) and clinical (29) studies demonstrated that the practice of physical activity before or during pregnancy reduced the risk of lumbopelvic pain. However, a study (30) was carried out with 855 pregnant women aimed to evaluate a 12-week exercise program during the second half of pregnancy on the prevalence of lumbopelvic pain and the number of medical licenses in the period; revealed that the program did not appear to influence the prevalence, but significantly reduced the proportion of women applying for sick leaves for this condition. Those results suggested that they can cope better with the disorder compared to women who received standard prenatal care.

Inactivity may be a predisposing factor to painful experiences (30) and a cross-sectional study (3) showed that there is an association of gestational low back pain with the longer time spent in the lying position, independent of the mattress characteristic. However, for pregnant women with low back pain, rest may be a strategy to relieve symptoms, since our study revealed that the majority $(76.7 \%)$ found pain relief at bedtime, sit or relax, not related to lumbar incapacity. Previous studies $(8,14)$ also reported improvement of the symptom with rest, possibly related to muscle relaxation (12), and worsened with the orthostatic position. Also, according to the participants, our study revealed that the walking, and this is significantly related to lumbar incapacity, possibly due to overload in the musculoskeletal system (14), but also, to the increase of the width of the step that consumes more energy and the longer time of maintenance of the feet on the ground, decreasing the simple support time, used as strategy for greater stability and support of body weight (25).

Different clinical tests can be used to identify the origin of this painful condition. The European community (20) has defined that pelvic pain is a specific type of low back pain, which can occur alone or in conjunction with low back pain. Its diagnosis should be based on the use of different clinical tests, including: Posterior Pelvic Pain Provocation test, Gaenslens test and ASLR $(13,20,21)$. As well as the PPPP test $(6,31)$ has high sensitivity and specificity for posterior pelvic pain, the lumbar pain provocation test can be used in the diagnosis of gestational low back pain $(11,18)$. Our study revealed that posterior pelvic pain was less frequent (23.4\%) followed by low back pain (36.6\%), most of which were combined (40\%). Previous study (14) of prevalence that have used specific clinical trials for low back pain are rare because different criteria can be used to characterize the origin of pain. A study (6) of 64 women reported gestational lumbopelvic pain, found that $17 \%$ identified the lumbar region as a site of pain, 33\% of the pelvic region and $50 \%$ of both. However, this study differentiated the origin of the pain only by the use of a body diagram. Another study (4) found a similar prevalence for the origin of pain in the body diagram, and revealed that the combination of the two pain sites results in a higher rate of lumbar incapacity in the ODI compared to women who present these pain conditions in only one region. In agreement with such researchers, the fact that different regions have been identified as a site of pain between the different studies may be explained by the inability of most women to anatomically locate pain in a drawing/diagram, making the specific clinical test extremely important to their clarification.

Therefore, corroborating our findings, a clinical study (18) to evaluate the effects of the intervention 
of gestational low back pain with yoga affirmed that before the intervention, $17 \%$ of pregnant women presented lumbar pain (proven by means of the lumbar pain provocation test), $20 \%$ presented posterior pelvic pain (proven by the PPPP test), but the majority $(63.3 \%)$ presented a combination of both. The different results found with the proposed intervention indicate that the success of the kinesio therapeutic intervention has some relation with the correct identification of the origin of the pain.

Also, in our study, it was possible to notice that the positivity in the different tests presented a correlation with the severity of the lumbar incapacity, except for the Laségue test, suggesting that this population rarely presents neural involvement during this period $(11,19)$. These data reveal the importance of using specific clinical tests to identify the origin of the pain, but the combination of tests should be explored in future research to assist in the determination of lumbopelvic pain (5).

It is recognized in the literature that the relaxin hormone promotes greater ligament elasticity in the joints, leading to increased joint mobility (14), which leads to greater demands on muscle and ligament stabilization (31). However, our study revealed that women with lumbopelvic pain had a decrease in joint amplitude (especially for flexion and extension) of the lumbar spine in all movements, as well as lumbar flexibility, these being related to the increase of the lumbar incapacity. This may reveal that the presence of pain can lead to joint restraints, possibly due to the needs imposed on the ligaments and stabilizing muscles, causing muscle spasm.

It is known that physical capacity decreases in the last gestational trimester, being even more limited to pregnant women with low back pain $(23,26)$. In our study, physical performance and overall trunk mobility was assessed by the Back Performance Scale in terms of five domains. That is, the ability to wear a sock test, to reach objects on the floor from the sit-up (Pick-up test), to sit (Roll-up test), to reach the ground from the orthostatic position (Fingertip-Floor test) and withstand a weight of $5 \mathrm{~kg}$ for one minute (Lift test). It was verified that the majority of the women presented limitation to the accomplishment of these activities and there was a positive correlation with the lumbar incapacity (measured by the ODI), that is, the higher the limitation in the physical performance and general mobility of the trunk, the more severe the incapacity low back.
In contrast to these findings, a study with pregnant in the third gestational trimester (26) found that all of them were able to perform the functional activities evaluated by Katz's Activity Daily Index (bathing, dressing, going to the toilet, performing transfers, maintaining continence and eating) independently, with no correlation with lumbar disability. The contradictory results may be due to the different instruments evaluated for physical capacity measurement. However, the functional scores obtained in the study were worse in comparison to those who did not report low back pain. In this way, pregnant with low back pain presented a strong correlation between pain intensity and physical capacity, corroborating our findings.

It is emphasized that the results of this study should be interpreted with caution, as it has a crosssectional design, and the correlations found do not necessarily imply causality (3). For example, the association of lumbar disability with higher levels of pain intensity, presence of lumbar pain musculoskeletal specific tests, greater limitation of lumbar amplitude (flexion and extension), lumbar flexibility, and lower trunk mobility may be associated with higher levels of pain intensity. Interpreted as indicating that these factors increase disability or, conversely, as an indication that they are consequences of disability. However, it is unlikely that a causal factor shows no association with the corresponding condition (3). Therefore, cross-sectional studies are useful in identifying the variables that should be included in prospective studies. However, the sample size of our study has no statistical power to draw definitive conclusions.

\section{Conclusion}

According to the results of this study, it was possible to identify that $93.8 \%$ of the women reported the presence of pain in the lumbar region during the gestational period. This was the most cited region for the occurrence of musculoskeletal discomforts, reported by the majority of women (56.3\%) with periodicity always present in the gestational period. Pain is characterized in the majority of pregnant women, having a daily frequency (63.3\%), with the first episode after 14 weeks (90\%), being the main triggering factor the prolonged walk without professional orientation 
(36.7\%) classified as high intensity (50\%), generating mild incapacity (40.6\%).

We have also shown that increased lumbar incapacity during pregnancy is associated with positive clinical trials (in particular, the lumbar pain provocation test), decreased joint amplitude (especially lumbar spine flexion and extension), decreased lumbar flexibility and of general trunk mobility. This represents an important aspect to be observed in the obstetric evaluation and they become important goals in the program planning of preventive or corrective exercises for this condition.

We suggest, for further researches, randomized clinical trials to evaluate the efficacy of treatments or preventive measures for lumbopelvic pain gestational, and should include specific tests for low back pain, assessment of range of motion and flexibility, as well as evaluation of general trunk mobility, to help in clarifying these issues.

\section{References}

1. Ramachandra P, Maiya AG, Kumar P, Kamath A. Prevalence of musculoskeletal dysfunctions among Indian Pregnant Women. J Pregnancy. 2015;2015:437105.

2. Thabah M, Ravindran V. Musculoeskeletal problems in pregnancy. Rheumatol Int. 2015;35(4):581-7.

3. Kovacs FM, Garcia E, Royuela A, Gonzalez L, Abraira V. Prevalence and factors associated with low back pain and pelvic girdle pain during pregnancy: a multicenter study conducted in the Spanish National Health Service. Spine. 2012;37(17):1516-33.

4. Malmqvist S, Kjaermann I, Andersen K, Økland I, Brønnick K, Larsen JP. Prevalence of low back and pelvic pain during pregnancy in a Norwegian Population. J Manipulative Physiol Ther. 2012;35(4):272-8.

5. Mens JM, Huis in't Veld YH, Pool-Goudzwaard A. Severity of signs and symptoms in lumbopelvic pain during pregnancy. Man Ther. 2012;17(2):175-9.

6. Pierce H, Homer CSE, Dahlen HG, King J. PregnancyRelated Lumbopelvic Pain: listening to Australian women. Nurs Res Pract. 2012;2012:387428.
7. Gutke A, Olsson CB, Völlestad N, Öberg B, Wikmar LN, Robinson HS. Association between lumbopelvic pain, disability and sick leave during pregnancy - a comparison of three Scandinavian cohorts. J Rehabil Med. 2014;46(5):468-74.

8. Madeira HGR, Garcia JBS, Lima MVV, Serra HO. Incapacidade e fatores associados à lombalgia durante a gravidez. Rev Bras Ginecol Obstet. 2013;35(12):541-8.

9. Bastiaenen $\mathrm{CH}$, de Bie RA, Vlaeyen JW, Goossens ME, Leffers P, Wolters PM, et al. Long-term effectiveness and costs of a brief self-management intervention in women with pregnancy-related low back pain after delivery. BMC Pregnancy Childbirth. 2008;8:19.

10. Vermani E, Mittal R, Weeks A. Pelvic girdle pain and low back pain in pregnancy: a review. Pain Pract. 2010;10(1):60-71.

11. 11. Martins RF, Silva JLP. Prevalência de dores nas costas na gestação. Rev Assoc Med Bras. 2005;51(3):144-7.

12. Santos MM, Gallo AP. Lombalgia gestacional: prevalência e características de um programa pré-natal. Arq Bras Ciên Saúde. 2010;35(3):174-9.

13. Lima AS, Gomes MRA, Araújo RC, Pitangui ACR. Análise da postura e frequência de lombalgia em gestantes: estudo piloto. J Health Sci Inst. 2011;29(4):290-3.

14. Gomes MRA, Araújo RC, Lima AS, Pitangui ACR. Lombalgia gestacional: prevalência e características clínicas em um grupo de gestantes. Rev Dor. 2013;14(2):114-7.

15. 15. Pinheiro FA, Troccoli BT, Carvalho CV. Validação do Questionário Nórdico de Sintomas Osteomusculares como medida de morbidade. Rev Saúde Pública. 2002;36(3):307-12.

16. Farrar JT, Young JP Jr, LaMoreaux L, Werth JL, Poole RM. Clinical importance of changes in chronic pain intensity measured on an 11-point numerical pain rating scale. Pain. 2001;94(2):149-58.

17. Vigatto R, Alexandre NM, Correa Filho HR. Development of a Brazilian Portuguese version of the Oswestry Disability Index: cross-cultural adaptation, reliability, and validity. Spine. 2007;32(4):481-6. 
18. Martins RF, Pinto e Silva JL. Treatment of pregnancyrelated lumbar and pelvic girdle pain by the yoga method: a randomized controlled study. J Altern Complement Med. 2014;20(1):24-31.

19. Magee DJ. Avaliação Musculoesquelética. 5th ed. São Paulo: Manole; 2010.

20. Vleeming A, Albert HB, Östgaard HC, Sturesson B, Stuge B. European guidelines for the diagnosis and treatment of pelvic girdle pain. Eur Spine J. 2008;17(6):794-819.

21. Kanakaris NK, Roberts CS, Giannoudis PV. Pregnancy-related pelvic girdle pain: an update. BMC Med. 2011;9:15.

22. Marques AP. Manual de goniometria. 3rd ed. São Paulo: Manole; 2014.

23. Strand LI, Moe-Nilssen R, Ljunggren AE. Back Performance Scale for the assessment of mobility-related activities in people with back pain. Phys Ther. 2002;82(12):1213-23.

24. Hopkins WG. Measures of reliability in sports medicine and science. Sports Med. 2000;30(1):1-15.

25. Branco M, Santos-Rocha R, Vieira F. Biomechanics of gait during pregnancy. Sci World J. 2014;2014:527940.

26. Coban A, Arslan GG, Colakfakioglu A, Sirlan A. Impact on quality of life and physical ability of pregnancyrelated back pain in the third trimester of pregnancy. J Pak Med Assoc. 2011;61(11):1122-4.
27. Yoo H, Shin D, Song C. Changes in the spinal curvature, degree of pain, balance ability, and gait ability according to pregnancy period in pregnant and nonpregnant woman. J Phys Ther Sci. 2015;27(1):279-84.

28. Mogren IM. Previous physical activity decreases the risk of low back pain and pelvic pain during pregnancy. Scand J Public Health. 2005;33(4):300-6.

29. Mørkved S, Salvesen KA, Schei B, Lydersen S, Bø K. Does group training during pregnancy prevent lumbopelvic pain? A randomized clinical trial. Acta Obstet Gynecol Scand. 2007;86(3):276-82.

30. Stafne SN, Salvesen KÅ, Romundstad PR, Stuge B, Mørkved S. Does regular exercise during pregnancy influence lumbopelvic pain? A randomized controlled trial. Acta Obstet Gynecol Scand. 2012;91(5):552-9.

31. Olsén MF, Gutke A, Elden H, Nordenman C, Fabricius L, Gravesen M, et al. Self-administered tests as a screening procedure for pregnancy-related pelvic girdle pain. Eur Spine J. 2009;18(8):1121-9.

Received in 09/11/2015

Recebido em 11/09/2015

Approved in 11/16/2016

Aprovado em 16/11/2016 